\title{
Educação infantil: da diversidade de oferta aos novos locais de governança
}

\author{
Early childhood education: offering diversity to the new local governance
}

Educación infantil: ofreciendo diversidad a los nuevos locales del gobierno

\author{
ZARA FIGUEIREDO TRIPODI*
}

\begin{abstract}
RESUMO
Este texto apresenta resultados preliminares de pesquisa que tem sido realizada no âmbito de pós-doutorado, no Centro de Estudos da Metrópole - USP/Cebrap. Busca-se examinar, aqui, as principais tendências de expansão da educação infantil pelos municípios, tendo como referência o novo Plano Nacional de Educação. Inicialmente, fazse uma breve retrospectiva dos marcos regulatórios da educação infantil. Discute-se, em seguida, o federalismo, a reforma do aparelho do Estado (1995) e sua interface com a educação das crianças pequenas. A instituição do PNE, as metas das capitais brasileiras para a primeira etapa da educação básica e os novos locais de governança são o foco de atenção seguinte do texto. Por fim, conclui-se que a publicação da Lei no 13.019/2014 concorre para reafirmar a tendência de oferta da educação infantil pelo setor público não estatal, tendo em vista as metas do PNE.
\end{abstract}

Palavras-chave: Educação infantil. Política educacional. Plano Nacional de Educação. Governança.

\begin{abstract}
The aim is to examine the main trends in this text expansion of early childhood education by municipalities, with reference to the new National Education Plan. At first, it makes a brief review of regulatory frameworks in early childhood education. It is argued, then federalism, reform of the state apparatus (1995) and its interface with the education of young children. The institution of the NAP, the goals of the Brazilian capital for the first stage of basic education and the new local governance are the focus of attention following text. Finally, it is concluded that the publication of Law no 13.019 / 2014 contributes to reaffirm the trend of offering early childhood education by nonstate public sector, in view of the PNE goals.
\end{abstract}

Keywords: Early childhood education. Educational policy. National Education Plan. Governance.

\section{RESUMEN}

Este texto presenta resultados preliminares de investigación, que se han llevado a cabo en el ámbito postdoctoral, en el Centro de Estudios Metropolitana - USP/Cebrap. Buscando examinar, las principales tendencias de expansión en la educación infantil por los municipios, teniendo como referencia el nuevo Plan Nacional de Educación. Inicialmente se realizó un breve análisis retrospectivo de los marcos regulatorios en la Educación Infantil. Seguidamente se discute, el federalismo, la reforma de estado (1995) y la interface con la educación de los niños. La institución PNE, las metas de las capitales brasileras para la primera etapa de educación básica y los nuevos locales del gobierno son foco de atención en el presente texto. Por último, se concluye que la publicación de Ley no 13.09/2014 contribuya a reafirmar la tendencia de ofrecer educación infantil por el sector público no estatal, en vista de los objetivos planteados por la PNE.

Palabras claves: Educación infantil. Política educacional. Plan Nacional de Educación. Gobierno.

\footnotetext{
* Doutorado em Educação pela FEUSP, com estágio pós-doutoral realizado no Centro de Estudos da Metrópole USP/CEBRAP; Professora do Departamento de Política e Planejamento Educacional da Universidade Federal do Paraná. E-mail: <zarafigueiredo@gmail.com>.
} 


\section{INTRODUÇÃO}

Prestes a completar três décadas de inscrição na Constituição Federal, que se dará em 2018, a agenda da educação infantil tem como uma de suas marcas a hibridez de atores e instituições inscritos na sua oferta, o que vem permitindo gradual aumento do atendimento desse direito social ao longo de quase 30 anos.

$\mathrm{Na}$ verdade, pode-se considerar que, desde os anos de 1970, conforme assinalam Campos, Bhering e Esposito (2010), assiste-se à expansão do ensino para as crianças pequenas, ainda que de forma desordenada, impulsionada, dentre outros fatores, pelo movimento social das mulheres brasileiras, pela modificação na organização e estrutura da família contemporânea e pelo reconhecimento das possibilidades e necessidades das crianças, explicitadas, sobretudo, pelo avanço do conhecimento científico na área.

Considerando a denúncia de que o atendimento à educação infantil, via convênios, especialmente no âmbito da creche, não é novo, a contribuição que se busca trazer neste artigo é discutir a tendência de intensificação da sua oferta. O que se dá por meio de arranjos institucionais cujo mote principal relaciona-se à formalização de parcerias com atores externos ao aparelho estatal, tendo em vista as metas postas ao municípios pelo Plano Nacional de Educação (2014-2024).

Para tanto, o artigo será organizado em duas seções. Inicialmente, busca-se inserir a questão da educação infantil no contexto do federalismo brasileiro, pósmunicipalização, e dos princípios da reforma gerencial, empreendida pelo Ministério da Administração Federal e pela Reforma do Estado (1995). A seção posterior discute a Lei no 13.005/2014, que aprova o Plano Nacional de Educação no que concerne às metas para a educação infantil, enfatizando aquelas relativas às capitais brasileiras, as quais contam com maior aporte de recursos e maior capacidade institucional em relação aos municípios do interior. Na última seção, apresentam-se as formas de oferta da educação infantil que, tendencialmente, poderão ser acolhidas pelos municípios.

\section{FEDERALISMO, REFORMA DE ESTADO E GESTÃO DA EDUCAÇÃO}

Um estudo exploratório dos locais de governança da educação infantil não pode prescindir de considerar dois importantes fatores: o primeiro diz respeito ao novo papel assumido pelos entes municipais, pós-Constituição de 1988, e à subsequente redefinição do padrão de relações intergovernamentais. Já o segundo fator relaciona-se à convergência entre a ascensão da educação infantil como direito reconhecido constitucionalmente, em 1988, e o movimento de reforma do Estado que começa a se desenhar no Brasil, a partir dos anos de 1990. Processo que vai assumir contornos mais definidos com o Plano Diretor de Reforma do Aparelho do Estado (PDRAE, 1995) no contexto do Ministério da Administração Federal e Reforma do Estado (Mare), que, àquela altura, já apontava para uma direção contrária à regulação das atividades sociais por parte do Estado, na medida em que introduzia o conceito de público não estatal.

AConstituição de 1988, objetivando implementar uma agenda democratizante para o país, dá início a um processo intenso de descentralização, levando o Federalismo a se tornar um sistema triplo e, assim, concedendo aos municípios um lugar de destaque no cenário brasileiro. Embora um dos argumentos utilizados à época, de modo a sustentar a tese da descentralização, fosse o da melhoria da eficiência na alocação de recursos, Farah (2010) assevera que a ênfase concedida à descentralização, no contexto da democracia que se instaurava, relacionava-se, também, à associação entre centralização e autoritarismo. Segundo a autora,

O período ditatorial, iniciado em 1964, caracterizavase por grande centralização das políticas públicas no governo federal, com reduzida autonomia de ação dos demais níveis de governo. [...] Reivindicava-se, assim, a descentralização administrativa e dos serviços públicos; uma maior participação de estados e municípios enquanto agentes formuladores e gestores das políticas públicas e a inclusão da sociedade civil como ator político na formulação, implementação e controle das políticas. [...] As propostas de descentralização e de participação foram definidas por oposição às características centralizadoras e excludentes do período anterior, como estratégias fundamentais à democratização (FARAH, 2010, p. 148-149 - grifos do original).

Essa tese que associa positivamente descentralização à democracia, embora tenha sido contestada em trabalhos como o de Arretche (1999), tornou-se um consenso no Brasil e em outros países da América Latina, a partir do final dos anos de 1980. (MORDUCHOWICZ, 2011).

A nova condição de ente federado dos municípios foi seguida pelo aumento significativo de responsabilidades, sobretudo no campo do financiamento educacional, a partir de 1996, com a Emenda Constitucional no 14 que, ao instituir o Fundo de Manutenção e Desenvolvimento do Ensino Fundamental e de Valorização do Magistério (Fundef), induz um processo intenso de municipalização das matrículas do ensino fundamental.

Nesse sentido, ao examinar as causas e os efeitos do processo de "acirramento" da responsabilidade educacional dos municípios, Pinto (2014) argumenta que, nos últimos 60 anos da história do país, estes tinham sob 
sua competência cerca de um terço da matrícula total. Esse número sofreu uma rápida mudança com o Fundef, fazendo com que os municípios chegassem em 2013 com um percentual de $56 \%$ do total de matrículas. Levando em conta apenas a rede pública, esse número alcança o patamar de $69 \%$ das matrículas do ensino fundamental. Isso, em um contexto financeiro e orçamentário no qual, após transferências constitucionais de tributos, a União, em 2012, ficava com $60 \%$ da receita total, os Estados com $24 \%$ e os municípios com apenas $16 \%$, de acordo com dados da Receita Federal (PINTO, 2014).

O quadro se agrava ao considerar outro dado apresentado pelo autor em relação à estrutura educacional dos municípios, de acordo com a sua faixa de população. Segundo Pinto (2014), a despeito do rápido processo de municipalização impulsionada pelo Fundef, dados do Instituto Brasileiro de Geografia e Estatística (IBGE), de 2009, dão conta da seguinte situação:

[...] 57\% dos municípios não possuíam sequer uma secretaria exclusiva da educação, $48 \%$ não haviam constituído um sistema próprio de ensino e cerca de um terço não contava com um conselho municipal de educação com poderes deliberativos. Mais grave ainda, do ponto de vista do planejamento, é que $44 \%$ não tinham aprovado um plano municipal de educação; isso oito anos após a aprovação do Plano Nacional de Educação - PNE -, 2001-2011, que determinava que estados e municípios deveriam aprovar seus respectivos planos. O mais preocupante é que esses índices são praticamente equivalentes nos municípios com população até a faixa de 50 mil habitantes, que representam quase $90 \%$ do total de municípios brasileiros. [...] (Pinto, 2014, p. 05).

Contornos ainda mais preocupantes passam a ser delineados na medida em que se atenta para o Plano Nacional de Educação - PNE (2014-2024), instituído pela Lei $\mathrm{n}$ - 13.005/2014, e para as metas quantitativas previstas para a educação básica, sobretudo aquelas voltadas à educação infantil, sob competência prioritária dos municípios. Apenas o alcance da meta desse estrato educacional, no segmento creche e pré-escola, implica, segundo Pinto (2014), um adicional de 4,5 milhões de novas matrículas. Em um período que abrange o PNE e no qual as normas de cooperação entre os entes federados, conforme preconiza o art. 23, da Constituição Federal, não estão totalmente definidas.

De par com a questão da descentralização e municipalização do ensino, a análise da oferta da educação infantil exige que se considere o quadro mais amplo em que se insere a Reforma do Estado. Iniciada, no Brasil, na metade dos anos de 1990, coloca novos desafios para a educação de modo geral, e para o estrato infantil, de maneira específica.
A ênfase que se dá à necessidade de se tomar a reforma do aparelho estatal como objeto de análise, nesse contexto, advém, sobretudo, da reconfiguração do papel do Estado na provisão das políticas sociais como a educação. Esta, segundo o Pdrae, deveria ser prestada pelo setor considerado "não exclusivo" do Estado, também denominado setor público não estatal.

$\mathrm{Na}$ visão do então ministro do Mare e um dos idealizadores da reforma, Luiz Carlos Bresser-Pereira:

A reforma do Estado que está ocorrendo nos anos 90 deverá conduzir a um Estado fortalecido, com suas finanças recuperadas e com sua administração obedecendo a critérios gerenciais de eficiência. Mas a reforma também deverá alcançar o asseguramento pelo Estado que as atividades sociais, que não são monopolistas por natureza, sejam realizadas competitivamente pelo setor público não-estatal e por ele controladas ainda que com seu apoio financeiro, de maneira a conseguir a ampliação dos direitos sociais. Assim, inclusive como condição para o desdobramento de suas outras dimensões, a reforma requer alcançar a renovação do sistema político incorporando à própria participação cidadã mediante o controle social (BRESSER-PEREIRA; GRAU, 1999, p. 17 - grifos dos autores).

A proliferação das ideias em torno da reordenação do lugar do Estado na oferta dos serviços públicos e a subsequente introdução da figura do público não estatal no cenário das políticas públicas de cunho social estão relacionadas, ao que tudo indica, ao esgotamento do padrão de acumulação capitalista que prevaleceu no pós-guerra. $\mathrm{E}$ que provocou uma crise na capacidade do Estado em financiar as políticas sociais implantadas pelos governos social-democratas nas décadas anteriores, como sugerem Draibe e Henrique (1988). Além disso, o fim do socialismo com a queda da antiga União Soviética levou os movimentos sociais a serem colocados, também, sob questão. O que viabilizou a chegada de partidos conservadores ao poder, cujo direcionamento político-ideológico assentava-se numa perspectiva reducionista do aparelho estatal.

É, pois, nesse sentido, que Malta (1998) afirma que as críticas ao poder regulador do Estado, àquela altura, passaram a ser formuladas "não só a partir de posições que defendem a liberdade para o capital, mas também a partir de posições de esquerda". Se, de um lado, há a defesa da "mão invisível" do mercado concorrencial como sendo a melhor forma de controle econômico e social; de outro, critica-se o "poder estatal como sendo autoritário e contrário aos interesses da maioria" (MALTA, 1998, p. 37).

Esse estado de coisas, que passaria a viger a partir de meados dos anos 1990, tem como seu marco legal regulatório a Emenda Constitucional no 19, de 1998, que, dentre várias mudanças, altera o caput do art. 37, da Constituição Federal, introduzindo o princípio da 
eficiência à administração pública direta e indireta. E viabiliza, dessa forma, a gestão da coisa pública assentada numa lógica gerencial de gestão, de modo a, supostamente, produzir maior eficiência na oferta de serviços públicos.

A extinção do Mare, no segundo mandato do presidente Fernando Henrique Cardoso (1999-2002), impediu a mobilização das alianças e dos esforços necessários para a efetivação de algumas diretrizes constantes da Emenda Constitucional 19/1998, em âmbito federal, como, por exemplo, a possibilidade de demissão de servidor público estável por insuficiência de desempenho, sendo regulamentada por Lei Complementar. Porém muitos outros aspectos de abordagem gerencial foram incorporados desde então à gestão pública, sobretudo os arranjos que estabelecem e/ou intensificam as relações entre Estado e outros atores externos ao aparelho estatal na oferta de serviços sociais, como a educação.

Ao analisar a reforma gerencial de 1995, BresserPereira (2009) afirma que, do ponto de vista da saúde, com a criação do Sistema Único de Saúde (SUS), esta pode ser considerada exitosa, mas, na perspectiva da educação, é tida como um fracasso. Isso porque uma das suas metas, nesse sentido, era a transformação das universidades em fundações públicas, o que foi contestado, inclusive, por segmentos da situação e, portanto, aliados ao governo à época.

Contudo, se a escalada reformista, de um lado, não conseguiu atingir todos os seus objetivos, foi exitosa na medida em que as suas ideias passaram a ser disseminadas para os entes estaduais. Impulsionadas estas, principalmente, pela migração de burocratas do alto escalão do governo central para os Estados. Com o fim do Mare, não só difundiram as ideias do Plano Diretor, como também implementaram várias delas, chegando mesmo, em alguns casos, a "superar" o governo federal. Esse foi o caso do governo mineiro, no período de 2003 a 2014, que corresponde, respectivamente, à gestão de Aécio Neves e Antônio Anastasia (ABRUCIO, 2006; TRIPODI, 2014) e que introduziu uma série de ferramentas de modo a assentar o Estado em uma lógica gerencial bem definida.

No que se refere ao escopo deste artigo, chamam a atenção, dentre outros mecanismos mobilizados pelos Estados, e de forte inspiração no Pdrae, os novos locais de governança que passam a ser constituídos no âmbito das políticas públicas de cultura, meio ambiente e educação, sobretudo no estrato da educação infantil. Embora a análise das políticas públicas definidas para a educação infantil permita afirmar, como o fez Arelaro (2008), que a presença da esfera privada nesse âmbito tenha sido uma constante, essa "condição" parece estar se constituindo em uma opção permanente de oferta desse direito, assumindo novos contornos com os arranjos de natureza gerencial.

Isso significa dizer que a divisão do aparelho do Estado em quatro áreas - núcleo estratégico, atividade exclusiva, serviços não exclusivos, produção para o mercado -, assim como o fez o Pdrae, enfatizando a figura do público não estatal na oferta de serviços sociais, foi bem recebida pelos entes federados. Principalmente, os municipais, que em um cenário de recursos escassos e com a significativa demanda da educação infantil, sob sua responsabilidade, têm visto, nas parcerias com o terceiro setor, por meio de Organizações Sociais (OSs) e Organizações da Sociedade Civil de Interesse Público (Oscips), uma possibilidade de atendimento do direito à educação das crianças pequenas.

A leitura do Quadro 1 permite visualizar o movimento de normatização, no âmbito dos Estados, do terceiro setor, que passa a ser uma possibilidade de prestação de serviços de natureza social.

Quadro 1. Distribuição da legislação de Oscip nos Estados brasileiros, em 2013

\begin{tabular}{|c|c|c|}
\hline \multicolumn{3}{|c|}{$\begin{array}{l}\text { Abrangência da implementação de modelos de parcerias } \\
\text { com organizações da sociedade civil de interesse público no } \\
\text { Governo federal e nos Estados brasileiros }\end{array}$} \\
\hline Estado & Marco legal atualizado & $\begin{array}{c}\text { Ano de } \\
\text { implementação }\end{array}$ \\
\hline Governo federal & $\begin{array}{l}\text { Lei Federal 9.790, } \\
\text { de } 23 \text { de março de } 1999\end{array}$ & 1999 \\
\hline Acre & $\begin{array}{l}\text { Lei Estadual 1.428, } \\
\text { de } 2 \text { de janeiro de } 2002\end{array}$ & 2002 \\
\hline Amapá & $\begin{array}{l}\text { Lei Estadual 496, } \\
\text { de } 04 \text { de janeiro de } 2000\end{array}$ & 2000 \\
\hline Amazonas & $\begin{array}{l}\text { Lei Estadual 3.017, } \\
\text { de } 21 \text { de dezembro de } 2005\end{array}$ & 2005 \\
\hline Distrito Federal & $\begin{array}{l}\text { Lei Distrital 4.301, } \\
\text { de } 27 \text { de janeiro de } 2009\end{array}$ & 2009 \\
\hline Espírito Santo & $\begin{array}{l}\text { Lei } 564 \text {, } \\
\text { de } 20 \text { de julho de } 2010\end{array}$ & 2010 \\
\hline Goiás & $\begin{array}{l}\text { Lei Estadual } 15.731 \text {, } \\
\text { de } 07 \text { de julho de } 2006\end{array}$ & 2006 \\
\hline Maranhão & $\begin{array}{l}\text { Lei Estadual 7.462, } \\
\text { de } 8 \text { de novembro de } 1999\end{array}$ & 1999 \\
\hline Mato Grosso & $\begin{array}{l}\text { Lei Estadual } 8.687 \text {, } \\
\text { de } 24 \text { de julho de } 2007 \\
\text { Lei Estadual } 8.707 \text {, } \\
\text { de } 13 \text { de setembro de } 2007\end{array}$ & 2007 \\
\hline Minas Gerais & $\begin{array}{l}\text { Lei Estadual } 14.870 \text {, } \\
\text { de } 16 \text { de dezembro de } 2003\end{array}$ & 2003 \\
\hline Pernambuco & $\begin{array}{l}\text { Lei Estadual } 11.743 \text {, } \\
\text { de } 20 \text { de janeiro de } 2000\end{array}$ & 2000 \\
\hline Rio de Janeiro & $\begin{array}{l}\text { Lei Estadual } 5.501 \text {, } \\
\text { de } 07 \text { de julho de } 2009\end{array}$ & 2009 \\
\hline Rio Grande do Sul & $\begin{array}{l}\text { Lei Estadual } 12.901 \text {, } \\
\text { de } 11 \text { de janeiro de } 2008\end{array}$ & 2008 \\
\hline São Paulo & $\begin{array}{l}\text { Lei Estadual } 11.598 \text {, } \\
\text { de } 15 \text { de dezembro de } 2003\end{array}$ & 2003 \\
\hline Sergipe & $\begin{array}{l}\text { Lei Estadual 5.850, } \\
\text { de } 16 \text { de março de } 2006\end{array}$ & 2006 \\
\hline
\end{tabular}

Fonte: VILHENA e PROSDOCIMI, 2013. 
Se, por um lado, as parcerias com setores externos ao aparelho estatal têm se desenhado como uma possibilidade de atendimento ao direito constitucional dessa etapa da educação básica, principalmente para os municípios; por outro, arranjos dessa natureza parecem não se efetivar sem criar tensões na consolidação de valores públicos, como igualdade e cidadania, por exemplo (TRIPODI, 2014).

Para Rhodes (1996), o próprio termo governança já significa uma mudança de significado de governo, referindo-se, assim, a um processo de governação ou, ainda, a uma modificação nas condições de ordenação das normas ou dos métodos pelos quais uma sociedade é governada. Isto é, governança é um conceito mais amplo que governo, cobrindo atores não governamentais.

Nesse sentido, o que ocorre é uma dispersão do poder regulatório do Estado, embora essa dispersão não deva ser entendida como o seu afastamento do cenário educacional. Mesmo porque sua presença é condição necessária para a manutenção de um mercado educacional (ROBERTSON e VERGER, 2012), na medida em que é esse Estado que vai subsidiá-lo, ao mesmo tempo em que se vê redefinido pela interação com esses novos arranjos. Ao redefinir o seu papel, a esfera estatal passa a permitir que a oferta do ensino seja efetivada por outros atores, renunciando, parcialmente, à gestão e à organização direta do campo da educação, assumindo a condição de regulador da regulação ou, nos termos de Jessop (2003), adotando o "lugar" de uma metagovernança.

\section{A LEI №13.005/2014 E A INSTITUIÇÃO DOS PLANOS MUNICIPAIS DE EDUCAÇÃO}

Após três anos e meio de tramitação no Congresso, a Lei no 13.005, de 25 de junho de 2014, aprovou o Plano Nacional de Educação, com vigência de 10 anos, em conformidade com o art. 214, da Constituição Federal, e traz, já no seu art. 2º, as 10 diretrizes que deverão lhe presidir:

Art. 2o São diretrizes do PNE:

I - erradicação do analfabetismo;

II - universalização do atendimento escolar;

III - superação das desigualdades educacionais, com ênfase na promoção da cidadania e na erradicação de todas as formas de discriminação;

IV - melhoria da qualidade da educação;

$\mathrm{V}$ - formação para o trabalho e para a cidadania, com ênfase nos valores morais e éticos em que se fundamenta a sociedade;

VI - promoção do princípio da gestão democrática da educação pública;

VII - promoção humanística, científica, cultural e tecnológica do País;

VIII - estabelecimento de meta de aplicação de recursos públicos em educação como proporção do
Produto Interno Bruto - PIB, que assegure atendimento às necessidades de expansão, com padrão de qualidade e equidade;

IX - valorização dos(as) profissionais da educação; $\mathrm{X}$ - promoção dos princípios do respeito aos direitos humanos, à diversidade e à sustentabilidade socioambiental (BRASIL, 2014).

Essas diretrizes, como já apontado por Dourado (2010), sinalizam políticas educacionais de visão ampla, capazes de articular diferentes demandas da área educacional, como a universalização do atendimento escolar, passando pelo aspecto da qualidade, tanto do profissional quanto do ensino ofertado, e chegando à questão do financiamento. Chama a atenção, no conjunto dessas diretrizes, aquela relacionada à superação das desigualdades educacionais, devido à complexidade de tal tarefa, tendo em vista um país de dimensões continentais como o Brasil e com entes federados com capacidades institucionais tão díspares.

O plano, composto por 20 metas, tem como seu objetivo mais ousado avançar no que diz respeito ao reordenamento da lógica de planejamento e de concepção de políticas públicas educacionais. E assim inscrevê-las numa perspectiva de políticas de Estado, ao invés de políticas de governo, caracterizadas, estas últimas, pela descontinuidade política que marca o país, no âmbito específico da educação.

Nesse contexto, o art. $8^{\circ}$, em seu $\S 1^{\circ}$, é bastante significativo por estabelecer aos Estados, municípios e Distrito Federal os prazos e as bases sobre as quais se possa pensar a construção de um sistema nacional articulado de educação:

Art. 8o Os Estados, o Distrito Federal e os Municípios deverão elaborar seus correspondentes planos de educação, ou adequar os planos já aprovados em lei, em consonância com as diretrizes, metas e estratégias previstas neste PNE, no prazo de 1 (um) ano contado da publicação desta Lei.

$\S 1$ o Os entes federados estabelecerão nos respectivos planos de educação estratégias que:

I - assegurem a articulação das políticas educacionais com as demais políticas sociais, particularmente as culturais;

II - considerem as necessidades específicas das populações do campo e das comunidades indígenas e quilombolas, asseguradas a equidade educacional e a diversidade cultural;

III - garantam o atendimento das necessidades específicas na educação especial, assegurado o sistema educacional inclusivo em todos os níveis, etapas e modalidades;

IV - promovam a articulação interfederativa na implementação das políticas educacionais. [...] (BRASIL, 2014). 
De acordo com o dispositivo legal, todos os entes federados passam a ter como prazo para elaborarem ou adequarem os seus respectivos planos de educação o mês de junho de 2015, atentos às diretrizes, metas e estratégias estabelecidas na Lei 13.005/2014.

Se o art. 8o cuida de vincular os planos dos entes federados ao Plano Nacional de Educação, o art. 70 trata das condições para que as metas sejam cumpridas, haja vista que tanto o caput do artigo quanto seus parágrafos se debruçam sobre o regime de colaboração, como se pode ler pela transcrição abaixo:

Art. $7^{\circ}$ A União, os Estados, o Distrito Federal e os Municípios atuarão em regime de colaboração, visando ao alcance das metas e à implementação das estratégias objeto deste Plano.

$\S 1^{\text {o }}$ Caberá aos gestores federais, estaduais, municipais e do Distrito Federal a adoção das medidas governamentais necessárias ao alcance das metas previstas neste PNE.

$[\ldots]$

§ 4ํ Haverá regime de colaboração específico para a implementação de modalidades de educação escolar que necessitem considerar territórios étnicoeducacionais e a utilização de estratégias que levem em conta as identidades e especificidades socioculturais e linguísticas de cada comunidade envolvida, assegurada a consulta prévia e informada a essa comunidade.

§ 5ํㅡㄴ Será criada uma instância permanente de negociação e cooperação entre a União, os Estados, o Distrito Federal e os Municípios.

$\S 6^{\circ}$ O fortalecimento do regime de colaboração entre os Estados e respectivos Municípios incluirá a instituição de instâncias permanentes de negociação, cooperação e pactuação em cada Estado.

§ 70 O fortalecimento do regime de colaboração entre os Municípios dar-se--á, inclusive, mediante a adoção de arranjos de desenvolvimento da educação (BRASIL, 2014).

É importante sublinhar, nesse contexto, que apenas a educação enquanto política social é tratada na perspectiva de um regime de colaboração, explicitada pela Constituição Federal de 1988 e claramente assumida pela Lei no 13.005/2014, como possibilidade de se efetivarem as metas constantes do plano decenal. Essa excepcionalidade deve-se ao fato de o ensino fundamental estar vinculado tanto às redes municipais quanto estaduais (CURY, 2008).

Todavia, se o reconhecimento, pela Carta Magna, da necessidade de um regime de cooperação, de modo a assegurar o direito educacional, pode ser considerado um avanço, o texto constitucional não determinou as bases sobre as quais se daria essa colaboração, o que tem permitido arranjos políticos diversificados nessa esfera. Sobretudo aqueles que se assentam no reforço da coordenação intergovernamental, por meio da presença do governo federal, assumindo a centralidade das ações (ABRUCIO e SEGATTO, 2014).

No que se refere às tentativas legais de supressão das lacunas deixadas pela Constituição Federal, podem ser citadas a aprovação da Lei de Diretrizes e Bases da Educação, que passa a propor a necessidade de um Plano Nacional de Educação; a criação do Fundef; a organização do Sistema Brasileiro de Avaliação da Educação Básica (Saeb); a implementação do Plano de Desenvolvimento da Educação (PDE) e do Plano de Ações Articuladas (PAR).

Por um lado, todas essas iniciativas, em maior ou menor grau, acabam se tornando uma forma de lidar com as brechas orçamentárias deixadas pelo texto constitucional. Por outro, essas ações têm reforçado a coordenação federativa, exercida pelo Executivo federal, uma vez que estão vinculadas, de forma direta, à questão do financiamento, levando os entes federados a aceitaremnas, tendo em vista a escassez de recursos com que lidam municípios e Estados e as responsabilidades que lhe são devidas.

A Lei $\mathrm{n}$ - 13.005/2014, por sua vez, ainda que tenha dedicado um artigo exclusivo para tratar do regime de colaboração (art. 7으 e seus parágrafos), a regulamentação do Custo Aluno Qualidade Inicial (CAQI), que, em termos de financiamento, redefine a questão financeira da área educacional, ainda não foi efetivada pelo governo federal. Talvez porque, uma vez regulamentado o CAQi, a União se veria obrigada a comparecer com o aporte financeiro necessário de modo a cooperar com os entes federados na execução das políticas públicas educacionais., Com isso, perderia o seu poder de barganha para implementar políticas de seu interesse, entre as unidades subnacionais, utilizando para isso, o seu poder orçamentário.

O atraso na regulamentação do CAQi concorre para agravar a situação dos entes municipais, tendo em vista as metas propostas pelo PNE (2014-2024) e a situação financeira e institucional dessas unidades federadas. É nessa perspectiva que Abrucio e Segatto afirmam que "o grande desafio federativo da política educacional é fortalecer as capacidades institucionais dos municípios, em especial no que se refere à execução de suas ações", o que envolve, também, a problemática do financiamento (ABRUCIO e SEGATTO, 2014, p. 53).

\section{SOBRE A OFERTA DA EDUCAÇÃO INFANTIL}

A primeira meta do novo PNE é relativa à educação infantil, de responsabilidade prioritária dos municípios, e determina a esses entes que até 2016 o atendimento ao público da pré-escola, portanto de quatro e cinco anos, 
esteja universalizado. Além disso, a meta estipula que seja alcançado o percentual de $50 \%$ no atendimento de crianças de zero a três anos, em creches, até o último ano de vigência do plano, ou seja, 2024. O que implica o aumento de 4 milhões e meio de matrículas para o alcance da meta (PINTO, 2014) em um contexto no qual, embora tenha havido avanços importantes do ponto de vista do financiamento, o regime de colaboração ainda não está claramente definido.

O tamanho do desafio que a meta 01 impõe aos municípios pode ser lido no Quadro 2, no qual se tem retratado o percentual de atendimento da educação infantil, em 2014, nas capitais e nos seus respectivos Estados. Ressalta-se que foram priorizadas as capitais, uma vez que tendem a ter recursos mais expressivos que os municípios localizados no interior dos Estados.

Do conjunto de dados do Quadro 2, uma das informações que fica bastante visível diz respeito às desigualdades de oferta da educação infantil, considerando capital e Estado. À guisa de exemplo, tem-se o caso do Amazonas, na região Norte, em que os percentuais de atendimento de creche alcançam $13,1 \%$ na capital, Manaus, e um pouco mais de um terço desse valor no Estado, $4,7 \%$.

Pinto (2014), ao analisar os impactos da política de fundos no financiamento educacional dos municípios, aponta para a diferença existente entre a situação municipal no interior e na capital. Segundo o autor, ao se considerarem apenas os municípios com população superior a 50 mil habitantes, que correspondem a uma minoria dos municípios brasileiros, em 17 Estados da federação os municípios dispõem de pelo menos 50\% a mais de recursos por aluno que aqueles situados no interior

\section{SOBRE OS TIPOS DE INSTITUIÇÕES QUE VÊM ACOLHENDO A EDUCAÇÃO INFANTIL}

Analisando-se os dados anteriormente discutidos e sobretudo as metas do Plano Nacional de Educação, busca-se compreender as tendências de modos de regulação que pautarão as políticas públicas municipais destinadas à educação infantil para a próxima década, de modo a atingir as metas impostas pela Lei no 13.005/2014.

A hipótese aqui defendida é que os municípios tenderão a intensificar algumas formas de governança que já vêm se delineando e que privilegiam a forma de atuação dos governos em parceria com o setor público não estatal, nos termos definidos pelo Pdrae (1995) para atendimento desse estrato da educação básica. Motivados estes, principalmente, por três fatores, a saber: i) presença de um federalismo de colaboração impreciso, em que as bases cooperativas da União para com os municípios
Quadro 2. Percentual de atendimento dos Estados e capitais no segmento da educação infantil em 2014

\begin{tabular}{|c|c|c|c|}
\hline \multicolumn{2}{|l|}{ SUDESTE } & \multirow{2}{*}{\begin{tabular}{|c|}
$\begin{array}{c}\mathbf{0 - 3} \text { anos } \\
(\mathbf{\%})\end{array}$ \\
38,5 \\
32,1 \\
\end{tabular}} & \multirow{2}{*}{\begin{tabular}{|c|}
$\begin{array}{c}\text { 4-5 anos } \\
(\%)\end{array}$ \\
86,3 \\
87,6 \\
\end{tabular}} \\
\hline São Paulo & $\begin{array}{l}\text { São Paulo - capital } \\
\text { Estado }\end{array}$ & & \\
\hline Rio de Janeiro & $\begin{array}{l}\text { Rio de Janeiro - capital } \\
\text { Estado }\end{array}$ & $\begin{array}{l}33,9 \\
88,0\end{array}$ & $\begin{array}{l}27,5 \\
84,0\end{array}$ \\
\hline Minas Gerais & $\begin{array}{l}\text { Belo Horizonte - capital } \\
\text { Estado }\end{array}$ & $\begin{array}{l}34,7 \\
21,2\end{array}$ & $\begin{array}{l}85,2 \\
80,9\end{array}$ \\
\hline Espírito Santo & $\begin{array}{l}\text { Vitória - capital } \\
\text { Estado }\end{array}$ & $\begin{array}{l}52,9 \\
26,1\end{array}$ & $\begin{array}{l}97,2 \\
81,8\end{array}$ \\
\hline \multicolumn{4}{|l|}{ SUL } \\
\hline Rio Grande do Sul & $\begin{array}{l}\text { Porto Alegre - capital } \\
\text { Estado }\end{array}$ & $\begin{array}{l}30,5 \\
20,9\end{array}$ & $\begin{array}{l}60,2 \\
63,8\end{array}$ \\
\hline Paraná & $\begin{array}{l}\text { Curitiba - capital } \\
\text { Estado }\end{array}$ & $\begin{array}{l}39,5 \\
30,3\end{array}$ & $\begin{array}{l}83,6 \\
77,5\end{array}$ \\
\hline Santa Catarina & $\begin{array}{l}\text { Florianópolis - capital } \\
\text { Estado }\end{array}$ & $\begin{array}{l}47,5 \\
38,5\end{array}$ & $\begin{array}{l}87,3 \\
84,0\end{array}$ \\
\hline \multicolumn{4}{|l|}{ CENTRO-OESTE } \\
\hline Mato Grosso & $\begin{array}{l}\text { Cuiabá - capital } \\
\text { Estado }\end{array}$ & $\begin{array}{c}24 \\
15,9\end{array}$ & $\begin{array}{l}79,2 \\
71,8\end{array}$ \\
\hline Mato Groso do Sul & $\begin{array}{l}\text { Campo Grande - capital } \\
\text { Estado }\end{array}$ & $\begin{array}{l}29,8 \\
23,3\end{array}$ & $\begin{array}{l}808 \\
75,6 \\
\end{array}$ \\
\hline Goiás & $\begin{array}{l}\text { Goiânia - capital } \\
\text { Estado }\end{array}$ & $\begin{array}{l}18,7 \\
14,1\end{array}$ & $\begin{array}{l}67,2 \\
69,1\end{array}$ \\
\hline Distrito Federal & $\begin{array}{l}\text { Brasília - capital } \\
\text { Distrito Federal }\end{array}$ & $\begin{array}{l}23,2 \\
26,0\end{array}$ & $\begin{array}{l}80,7 \\
76,5 \\
\end{array}$ \\
\hline \multicolumn{4}{|l|}{ NORDESTE } \\
\hline Bahia & \begin{tabular}{|l|} 
Salvador - capital \\
Estado
\end{tabular} & $\begin{array}{l}29,5 \\
18,0\end{array}$ & $\begin{array}{l}88.5 \\
86.0\end{array}$ \\
\hline Ceará & $\begin{array}{l}\text { Fortaleza - capital } \\
\text { Estado }\end{array}$ & $\begin{array}{l}28,4 \\
22,1\end{array}$ & $\begin{array}{l}90.4 \\
93.0\end{array}$ \\
\hline $\begin{array}{l}\text { Rio Grande do } \\
\text { Norte }\end{array}$ & $\begin{array}{l}\text { Natal - capital } \\
\text { Estado }\end{array}$ & $\begin{array}{l}29,1 \\
25,6 \\
\end{array}$ & $\begin{array}{l}88.4 \\
89.7 \\
\end{array}$ \\
\hline Sergipe & $\begin{array}{l}\text { Aracaju - capital } \\
\text { Estado }\end{array}$ & $\begin{array}{l}29,2 \\
21,6 \\
\end{array}$ & $\begin{array}{l}89.3 \\
92.9 \\
\end{array}$ \\
\hline Alagoas & $\begin{array}{l}\text { Maceió - capital } \\
\text { Estado }\end{array}$ & $\begin{array}{l}25,1 \\
20,7 \\
\end{array}$ & $\begin{array}{l}81,7 \\
75,6 \\
\end{array}$ \\
\hline Pernambuco & $\begin{array}{l}\text { Recife - capital } \\
\text { Estado }\end{array}$ & $\begin{array}{l}35,6 \\
20,7 \\
\end{array}$ & $\begin{array}{l}90,9 \\
82,1 \\
\end{array}$ \\
\hline Piauí & $\begin{array}{l}\text { Teresina - capital } \\
\text { Estado }\end{array}$ & $\begin{array}{l}18,2 \\
16,2\end{array}$ & $\begin{array}{l}77,9 \\
93,9\end{array}$ \\
\hline Maranhão & \begin{tabular}{|l|} 
São Luís - capital \\
Estado
\end{tabular} & $\begin{array}{l}27,7 \\
15,1 \\
\end{array}$ & $\begin{array}{l}93,9 \\
87,2 \\
\end{array}$ \\
\hline Paraíba & $\begin{array}{l}\text { João Pessoa - capital } \\
\text { Estado }\end{array}$ & $\begin{array}{l}28,4 \\
17,1 \\
\end{array}$ & $\begin{array}{l}84,5 \\
87,8 \\
\end{array}$ \\
\hline \multicolumn{4}{|l|}{ NORTE } \\
\hline Acre & $\begin{array}{l}\text { Rio Branco - capital } \\
\text { Estado }\end{array}$ & $\begin{array}{l}9,8 \\
7,4 \\
\end{array}$ & $\begin{array}{l}72,4 \\
58,6 \\
\end{array}$ \\
\hline Amapá & $\begin{array}{l}\text { Macapá - capital } \\
\text { Estado }\end{array}$ & $\begin{array}{l}11,0 \\
8,5\end{array}$ & $\begin{array}{l}64,5 \\
62,4\end{array}$ \\
\hline Amazonas & $\begin{array}{l}\text { Manaus - capital } \\
\text { Estado }\end{array}$ & $\begin{array}{c}13,1 \\
4,7\end{array}$ & $\begin{array}{l}74,0 \\
63,6 \\
\end{array}$ \\
\hline Pará & $\begin{array}{l}\text { Belém - capital } \\
\text { Estado }\end{array}$ & $\begin{array}{l}22,2 \\
11,2\end{array}$ & $\begin{array}{l}83,7 \\
73,9 \\
\end{array}$ \\
\hline Rondônia & $\begin{array}{l}\text { Porto Velho - capital } \\
\text { Estado }\end{array}$ & $\begin{array}{l}15,3 \\
8,8 \\
\end{array}$ & $\begin{array}{l}67,3 \\
56,9 \\
\end{array}$ \\
\hline Roraima & $\begin{array}{l}\text { Boa Vista - capital } \\
\text { Estado }\end{array}$ & $\begin{array}{l}16,4 \\
11,6 \\
\end{array}$ & $\begin{array}{l}76,1 \\
73,8 \\
\end{array}$ \\
\hline Tocantins & $\begin{array}{l}\text { Palmas - capital } \\
\text { Estado }\end{array}$ & $\begin{array}{l}26,2 \\
12,1\end{array}$ & $\begin{array}{l}79,9 \\
67,4 \\
\end{array}$ \\
\hline
\end{tabular}

Fonte: PNE/MEC. Acesso em 12.05.2015. Elaboração própria. 
não estão claramente definidas; ii) natureza arrojada das metas da educação infantil destinadas aos municípios, num contexto de recursos escassos e de menor capacidade institucional; iii) edição da Lei no 13.019 , de 31 de julho de 2014, publicada um mês após a Lei no $13.005 / 2014$, que estabelece o regime jurídico das parcerias voluntárias, envolvendo ou não transferências de recursos financeiros, entre a administração pública e as organizações da sociedade civil, em regime de mútua cooperação, para a consecução de finalidades de interesse público.

Um dos desdobramentos dessa hipótese é que a suposta intensificação de parcerias com atores situados fora do aparelho estatal tem potencial para promover a reconfiguração do modelo de regulação do Estado. Levando-o, assim, a assumir um lugar de regulador da regulação ou de uma metagovernança (JESSOP, 2003) na área educacional.

$\mathrm{O}$ redimensionamento do lugar do Estado na oferta do direito social que é a educação pode ter como uma das consequências a intensificação das desigualdades, haja vista que se poderia ter uma distribuição desigual entre os iguais desse direito.

Nesse sentido, Cury (2008) adverte que, quando nem as vontades individuais, nem o sistema contratual de mercado são capazes de garantir a igualdade de condições de partida, somente a intervenção de um poder maior, que no caso é o Estado, poderá fazer do bem educacional um bem comum, para efeitos de igualdade. Portanto, uma das diretrizes que devem perpassar a oferta da educação infantil é a da igualdade de condições de oferta, assegurada, protegida e regulada pelo Estado.

O relatório final da pesquisa "Educação Infantil no Brasil - Avaliação Qualitativa e Quantitativa”, realizada pela Fundação Carlos Chagas, em 2010, traz elementos importantes que corroboram a tese aqui defendida. Isso porque a pesquisa constata que a dispersão do poder regulatório do Estado para outros locais de regulação tende a criar e, principalmente, a acolher níveis de desigualdade de oferta e qualidade no atendimento nessa etapa da educação. O que termina por consolidar uma situação em que alguns usuários do sistema passam a ser mais cidadãos que outros.

Essa pesquisa, a partir da qual o relatório é produto, foi realizada em seis capitais: Belém (PA), Campo Grande (MS), Florianópolis (SC), Fortaleza (CE), Rio de Janeiro (RJ) e Teresina (PI). Evidenciou como um dos traços mais marcantes a diversidade na composição do atendimento escolar e a desigualdade na capacidade de financiamento, as quais emergem da comparação dos sistemas municipais.

Um exemplo a esse respeito está no fator de ponderação de creches de tempo integral. De acordo com Campos, Bhering e Espósito (2010), os valores, além de subdimensionados, são diferentes entre o atendimento em creches públicas e conveniadas, sendo menores os valores dessa segunda modalidade Em última análise, isso se torna um elemento que pesa a favor dos municípios para que invistam nessa modalidade de atendimento, ao invés de ampliarem a rede pública própria. $O$ repasse feito pelas prefeituras às instituições conveniadas é, em larga medida, inferior ao valor do aluno repassado pelo Fundeb para as matrículas do ensino infantil, de acordo com a pesquisa.

Campos, Bhering e Espósito (2010) sublinham o imbricado conjunto de relações que têm se efetivado, pelo poder público, de modo a ampliar o escopo da ação estatal, regulamentando e consolidando o atendimento sob sua responsabilidade.

Observou-se, também, nesse conjunto, "vultosas somas de recursos públicos" transferidas para contratação de pessoal, como ficou evidenciado, segundo as autoras, nas Secretarias de Educação de Belém e Teresina. Estas contratavam estudantes de graduação em Pedagogia e licenciaturas para serem estagiários nas creches públicas, por meio de parceria com o Centro de Integração Escola-EmpresaCiee (CAMPOS, BHERING e ESPÓSITO, 2010, p. 335).

No contexto de contratação de pessoal, as autoras da pesquisa encontraram casos extremos, como o de Campo Grande (MS), em que o serviço conveniado é responsável pela maior parte do atendimento, e que " $62 \%$ dos dispêndios se encontram alojados na categoria Custeio (despesas correntes) e apenas $21 \%$ em pessoal e encargos sociais" (CAMPOS, BHERING e ESPÓSITO, 2010, p. 386). E apenas duas entidades são responsáveis pela contratação de todo o pessoal administrativo e de apoio da rede pública. Contudo, Teresina apresenta um quadro ainda mais complexo, haja vista que nesse município "cinco ou seis instituições sem fins lucrativos se encarregam da contratação de pessoal, incluindo contratação de docentes, os quais são alocados tanto para o setor privado quanto para o setor público, nesse caso atuando nas escolas ao lado de professores do quadro efetivo" (CAMPOS, BHERING e ESPÓSITO, 2010, p. 386).

Do ponto de vista da qualidade das creches e préescolas nas seis capitais, os resultados não são menos complexos e apontam para o comprometimento de uma fase essencial na formação do indivíduo, que é a educação infantil.

De modo geral, os achados da pesquisa permitiram algumas conclusões em torno da qualidade da educação oferecida nas entidades de educação infantil, como um todo, sem desagregar públicas de conveniadas. As análises indicaram, segundo as autoras, que as médias das pontuações obtidas pela aplicação das escalas de observação dos ambientes para crianças de creche e de pré-escola não correspondem a níveis adequados de qualidade. Segundo elas: 
Examinando-se as médias em cada uma das subescalas que compõem esses instrumentos, verificou-se que aspectos importantes de uma programação voltada para crianças nessas faixas etárias estão sendo negligenciados na maioria das instituições avaliadas.

Para as salas de creche, as médias das subescalas Atividades $(2,2)$ e Rotinas de cuidado pessoal $(2,9)$ foram as mais baixas, equivalendo ao nível de qualidade inadequado. As médias das subescalas Espaço e mobiliário $(3,1)$, Falar e compreender $(3,8)$, Estrutura do programa $(3,2)$ e Pais e equipe $(3,6)$ situaram-se no nível de qualidade básico e a subescala Interação obteve a maior média $(5,7)$, atingindo o nível de qualidade adequado.

Nas salas de pré-escola observadas, as médias das subescalas variaram entre 2,3 e 5,6, abrangendo os níveis de qualidade inadequado, básico e adequado. No nível inadequado estão as subescalas Atividades (2,3) e Estrutura do programa (2,5); no básico, encontramse as subescalas Espaço e mobiliário $(3,1)$, Pais e equipe $(3,6)$, Linguagem e raciocínio $(3,7)$ e Rotinas de cuidado pessoal $(4,1)$; e no adequado, apenas a subescala Interação $(5,6)$. [...]

Para as salas de pré-escola, a subescala inclui tipos de atividade e aspectos na maior parte correspondentes aos citados acima. São eles: Motricidade fina; Arte; Música e movimento; Blocos; Areia/água; Brincadeira de faz de conta; Natureza/ciências; Matemática/ número; Uso da TV, vídeo e/ou computador; Promoção da aceitação da diversidade. O único item que recebeu uma pontuação média acima do nível de qualidade inadequado foi o relativo à Matemática/número, com 3,3, básico. Natureza/ciências obteve a pontuação mais baixa $(1,6)$ do conjunto de itens.

A classificação no nível de qualidade inadequado significa que não se encontrou nenhum material disponível para as atividades naquelas áreas do currículo, tais como gravura, livro, material ou objeto relativo ao conhecimento sobre a natureza ( CAMPOS, BHERING e ESPÓSITO, 2010, p. 394-395 - grifos dos autores).

Cabe assinalar, entretanto, que, mesmo esses dados não se referindo apenas à rede conveniada, não se pode desconsiderar o fato de que essa modalidade de atendimento variava entre $5 \%$ e $16 \%$, no ano de 2009 . Portanto, a discussão da qualidade de oferta da educação infantil não prescinde que se leve em conta essa forma de atendimento, via setor público não estatal.

Dados de outra pesquisa publicada em 2006, realizada em 52 instituições de educação infantil, em quatro Estados, dão conta que, nas instituições sem fins lucrativos, os entrevistados das equipes em seu conjunto apresentavam o nível mais baixo de escolaridade (CAMPOS, COELHO e CRUZ, 2006).

A tendência que tem sido observada, em relação à presença das creches e pré-escolas conveniadas, tem contribuído para a composição de um cenário institucional pautado pela coexistência de locais de governança, nos termos colocados por Rhodes (1996), que parece pôr em questão a capacidade de realização do atendimento igualitário da educação infantil de qualidade. Tendo, assim, como base os achados de pesquisas anteriormente referenciadas, mas, sobretudo, tendo em vista que é a etapa da educação básica mais vulnerável, no sentido de se inscrever como um dever do Estado. Somente a partir de 1988 e menos de uma década depois, esse dever foi sendo disseminado para outros atores, em decorrência da reordenação dos papéis desse mesmo Estado.

\section{TENDÊNCIA DA OFERTA DA EDUCAÇÃO INFANTIL POR MEIO DO SETOR PÚBLICO NÃO ESTATAL}

Finaliza-se este artigo com uma indagação que reitera a urgência de busca por resposta a um questionamento feito por Arelaro (2008), em texto que discute parcerias público-privadas no contexto das creches: "Não seriam as creches conveniadas opção permanente de política para a educação infantil?" (p. 65).

A resposta a essa questão precisa ser construída não só por meio do dimensionamento da distribuição das matrículas por tipo de instituição ofertante. Deve ir além, buscando caracterizar, por meio da análise dos planos municipais de educação elaborados e/ou reformulados em 2015, as estratégias explicitadas pelos entes federados municipais para a oferta da educação infantil, relativas aos locais de governança.

Essa perspectiva supõe a análise não só do lócus de atendimento, mas principalmente, da noção de Estado que se institui e que reconfigura o modo como o direito à educação infantil vem sendo garantido.

O debate em torno das metas propostas pelo Plano Nacional de Educação e a publicação da Lei no 13.019/2014 apoiam a suposição de que a resposta dos municípios, via Planos Municipais de Educação, tenderá a se delinear por meio de alternativas não públicas de atendimento do direito à educação infantil. Essa lei estabelece o regime jurídico das parcerias voluntárias, envolvendo ou não transferências de recursos financeiros, entre a administração pública e as organizações da sociedade civil, em regime de mútua cooperação, para a consecução de finalidades de interesse público, praticamente concomitante à Lei 13.005/2014. Esta institui os compromissos dos municípios, Estados, Distrito Federal e União para a próxima década.

Talvez essa etapa da educação básica, por ter sido tardiamente incorporada como direito da criança e dever do Estado, seja a mais atingida no contexto de fragilização dos limites entre o público e privado. 


\section{REFERÊNCIAS}

ABRUCIO, Fernando Luiz; GAETANI, Francisco. Avanços e perspectivas da gestão pública nos Estados: agenda, aprendizado e coalizão. In: Avanços e Perspectivas da Gestão Pública nos Estados. Consad, Fundap, 2006.

ABRUCIO, Fernando Luiz. Os avanços e dilemas do modelo pós-burocrático: a reforma da administração pública à luz da experiência internacional recente. In: BRESSER PEREIRA; Luiz Carlos; SPINK, Peter. Reforma do Estado e Administração Pública Gerencial. Rio de Janeiro: Editora FGV, 2006, p. 173-199.

ABRUCIO, Fernando Luiz; SEGATTO, Catarina Ianni. O manifesto dos pioneiros e o federalismo brasileiro: percalços e avanços rumo a um sistema nacional de educação. In: CUNHA et al. (org.). O Sistema Nacional de Educação - diversos olhares 80 anos após o manifesto. Brasília: MEC/SASE, 2014. p. 40-57.

ARRETCHE, Marta. Mitos da descentralização: mais democracia e eficiência nas políticas públicas. Revista Brasileira de Ciências Sociais, São Paulo, Associação Nacional de PósGraduação e Pesquisa em Ciências Sociais - Anpocs, v. 11, n. 34, p. 111-141, fev. 1996.

BRASIL. Constituição da República Federativa do Brasil. São Paulo: Saraiva, 2012.

BRASIL. Instituto Nacional de Estudos e Pesquisas Educacionais Anísio Teixeira. Sinopse estatística da educação básica. Brasília, DF: Inep, 2014.

BRASIL. Lei no 13.005, de 25 de junho de 2014. Aprova o Plano Nacional de Educação - PNE e dá outras providências. Diário Oficial da União. Brasília, 2014.

BRASIL. Lei no 13.019, de 31 de julho de 2014. Diário Oficial da União. Brasília, 2014.

BRESSER-PEREIRA, Luiz Carlos; GRAU, Nuria Cunill. Entre o Estado e o mercado: o público não-estatal. In: BRESSER PEREIRA, Luiz Carlos; GRAU, Nuria Cunill. O público nãoestatal na reforma do Estado. Rio de Janeiro: FGV, 1999. p. 15-47.

CAMPOS, Maria Malta. (coord.); BHERING, Eliana Bahia; ESPOSITO, Yara. et al. Educação infantil no Brasil: avaliação qualitativa e quantitativa. São Paulo: Fundação Carlos Chagas; Ministério da Educação; Banco Interamericano de Desenvolvimento, 2010. (Relatório Final).

CAMPOS, Maria Malta. Educação infantil: o debate e a pesquisa. Cad. Pesq., Fundação Carlos Chagas, n. 101, p. 113-127, jul. 1997.

CAMPOS, Maria Malta; COELHO, Rita de Cássia; CRUZ, Silva Vieira. Consulta sobre a qualidade da educação infantil: Relatório Técnico Final. Textos FCC. São Paulo: Fundação Carlos Chagas, 2006.

CURY, Carlos Roberto Jamil. Um novo movimento da educação privada. In: ADRIÃO, Theresa; PERONI, Vera (org.). Público e privado na educação: novos elementos para o debate. São Paulo: Xamã Editora, 2008, p. 17-25.
DALE, Roger. A promoção do mercado educacional e a polarização da educação. Educação, Sociedade e Culturas, Porto, n. 2, p. 109-139, 1994.

DOURADO, Luiz Fernandes (org.). Plano Nacional de Educação (2011-2020): avaliação e perspectivas. Belo Horizonte; Goiânia: Editora UFG; Editora Autêntica, 2010.

DRAIBE, Sônia; HENRIQUE, Wilnês. "Welfare state", crise e gestão da crise: um balanço da literatura internacional. Revista Brasileira de Ciências Sociais, Associação Nacional de PósGraduação e Pesquisa em Ciências Sociais - Anpocs, v. 3, n. 6, fev., 1988.

FARAH, Marta Ferreira Santos. Gestão Pública Municipal e Inovação no Brasil. In: ANDREWS, Christina W.; BARIANI, Edison. Administração Pública no Brasil - Breve História Política. São Paulo: Editora Unifesp, 2010.

GIDDENS, Anthony. A terceira via. Reflexões sobre o impasse político atual e o futuro da social-democracia. Rio de Janeiro; São Paulo: Record, 2005.

GOLDSMITH, Stephen; EGGERS, Willian D. Governar em rede. O novo formato do setor público. Brasília: Enap, 2011.

JESSOP, Bob. The future of the capitalist state. Cambridge: Polity Press, 2003.

MARE (Ministério de Administração e Reforma do Estado). Plano Diretor da Reforma Administrativa do Aparelho do Estado. Brasília: Mare, 1995.

MORDUCHOWICZ, Alejandro. La asignación de recursos en sistemas educativos descentralizados de América Latina. In: GOUVEIA, Andréa B.; PINTO, José Marcelino R.; CORBUCCI, Paulo Roberto (org.). Federalismo e políticas educacionais na efetivação do direito à educação no Brasil. Brasília, DF: Ipea, 2011. p. 13-28.

PERONI, Vera. A relação público/privado e a gestão da educação em tempos de redefinição do papel do Estado. In: ADRIÃO, Theresa; PERONI, Vera (org.). Público e privado na educação: novos elementos para o debate. São Paulo: Xamã Editora, 2008. p. 111-127.

PINTO, José Marcelino Rezende. Federalismo, descentralização e planejamento da educação: desafios aos municípios. Cad. Pesq., Fundação Carlos Chagas, v. 44, n. 153, p. 624-644, jul.-set. 2014.

ROBERTSON, Susan; VERGER, Antoni. A origem das parcerias público-privadas na governança global da educação. Educ. Soc. Centro de Estudos Educação e Sociedade Cedes, v. 33, n. 121, p. 1133-1156, out.-dez, 2012.

RHODES, R. A. W. The new governance: governing without government. In: Political Studies, XLIV, 1996. p. 652-667.

TRIPODI, Maria do Rosário Figueiredo. A instituição da agenda contratual na educação mineira: arquitetura de uma reforma, 2014, 313 p. Tese (Doutorado em Educação) Programa de Pós-Graduação em Educação, Universidade de São Paulo, São Paulo, 2014.

Submetido em 15/09/2015

Aprovado em 23/03/2016 